\title{
Long-term changes in computed tomography and ultrasound utilization in a pediatric emergency department
}

\section{Ikwan Chang', Jae Yun Jung ${ }^{2}$, Young Ho Kwak', Do Kyun Kim', Jin Hee Lee', Jin Hee Jung ${ }^{3}$, Hyuksool Kwon², So Hyun Paek', Joong Wan Park ${ }^{1}$}

Department of Emergency Medicine, ${ }^{1}$ Seoul National University Hospital, Seoul; ${ }^{2}$ Seoul National University Bundang Hospital, Seongnam; ${ }^{3}$ SMG-SNU Boramae Medical Center, Seoul, Korea

Objective Many studies have proposed reducing unnecessary use of computed tomography (CT), and ongoing studies in pediatric populations are aiming to decrease radiation dosages whenever possible. We aimed to evaluate the long-term changes in the utilization patterns of CT and ultrasound (US) in pediatric emergency departments (PEDs).

Methods This retrospective study reviewed the electronic medical data of patients who underwent CT and/or US in the PED of a tertiary referral hospital from 2000 to 2014. We compared the changes in utilization patterns of brain and abdominal CT scans in pediatric patients and analyzed changes in abdominal US utilization in the PED.

Results During the study period, 196,371 patients visited the PED. A total of 12,996 brain and abdominal CT scans and 12,424 abdominal US were performed in the PED. Comparison of CT use in pediatric patients before and after 2007 showed statistically decreasing trends after 2007, expressed as the coefficient values of the differences in groups. The numbers of brain and abdominal CT scans showed a significant decreasing trend in children, except for abdominal CT in adolescents. The abdominal US/CT ratio in the PED showed a statistically significant increase (2.68; 95\% confidence interval, 1.87 to 3.49 ) except for the adolescent group (5.82; 95\% confidence interval, -2.06 to 13.69$)$.

Conclusion Overall, CT use in pediatric patients has decreased since 2007. Pediatric US use has also shown a decreasing trend; however, the abdominal US/CT ratio in pediatric patients showed an increasing trend, except for adolescents.

Keywords Emergency service, hospital; Computed tomography; Diagnostic imaging; Child
eISSN: 2383-4625

Received: 2 July 2017

Revised: 30 September 2017

Accepted: 20 October 2017

Correspondence to: Jae Yun Jung Department of Emergency Medicine, Seoul National University Bundang Hospital, 82 Gumi-ro 173beon-gil, Bundang-gu, Seongnam 13620, Korea E-mail:matewoos@gmail.com

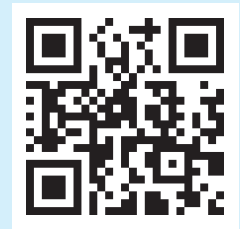

How to cite this article:

Chang I, Jung JY, Kwak YH, Kim DK, Lee JH, Jung JH, Kwon H, Paek SH, Park JW. Longterm changes in computed tomography and ultrasound utilization in a pediatric emergency department. Clin Exp Emerg Med 2018;5(1):35-42

This is an Open Access article distributed under the terms of the Creative Commons Attribution Non-Commercial License (http:// creativecommons.org/licenses/by-nc/4.0/). 


Capsule
What is already known
Pummary
Previous studies on computed tomography (CT) in pediatric patients reported the radiation hazard of CT to children. Re-
cent studies on the trends in CT use in emergency departments (EDS) showed that CT use has not decreased. In some ar-
ticles, the trend showed an increase in CT use. In contrast to these studies, a study on the trends of CT use at pediatric
ED in Korea has shown decreased usage since 2007. However, this study had shown the trend in CT and references
based on data from 2000 to 2010. In addition, this article reported only the trends in CT use.
What is new in the current study
Our findings revealed differences in the trends before and after 2007, in which CT use decreased after 2007 and the ul-
trasound/CT ratio increased after 2007 at a tertiary referral hospital between 2000 and 2014 . However, the results of
this study cannot represent the CT and ultrasound trends of all hospitals in Korea because the data used in this study
were collected in a single hospital. However, our results may be applicable to other EDs.

\section{INTRODUCTION}

Computed tomography (CT) utilization has been steadily increasing since its introduction in the 1970s, with usage increasing exponentially in the past two decades. ${ }^{1-5}$ Because CT is a useful and easily accessible tool for rapid evaluation and diagnosis, its utilization has markedly increased in emergency departments (EDs). ${ }^{2-6}$

With its increased usage, however, concern has been raised regarding the development of malignant diseases upon exposure to high radiation doses. Since the 2000s, the results of several studies have suggested that increased radiation exposure increases the risk of neoplasms, especially in pediatric populations. ${ }^{7-12}$ Pediatric populations have more active cellular division and smaller body areas, which lead to longer half-life for the elimination of radiation and thus greater dosage accumulation. ${ }^{13}$

Many studies have proposed reducing unnecessary CT imaging. Ongoing studies in pediatric populations aim to decrease radiation dosages as much as possible, even in situations considered mandatory for CT use. ${ }^{14-18}$ In accordance with these trends, our institution has been trying to reduce unnecessary diagnostic tests, especially CT, since 2007, in order to reduce exposure of pediatric patients to radiation hazards and promote utilization of ultrasound (US) examination. This study evaluated the trends in CT and US use before and after 2007 in pediatric emergency departments (PEDs).

\section{METHODS}

\section{Study population}

The adult ED and PED of the study hospital (a tertiary referral hospital) have operated independently with regard to their venues, equipment, and personnel since 1985. Patients below 19 years of age are usually recommended to visit the PED. All patients who visited the PED from January 2000 to December 2014 were included in this study.

\section{Study design and data collection}

This retrospective observational study reviewed institutional electronic medical records in order to analyze trends in CT and US utilization in the PED. Demographic data (age and gender); the annual number of ED visits; total, brain, and abdomen CT examinations; and total abdominal US examinations performed in the PED were obtained from electrical medical records.

The institutional review board of our hospital approved this retrospective study (no. H-1111-110-387) and waived the requirement for informed consent.

\section{Intervention to reduce CT}

Since 2007, in response to several study reports on the harmful effects of CT, PED physicians and radiologists in our institution have been working to reduce unnecessary imaging studies (especially CT) in order to reduce exposure of pediatric patients to radiation hazards. ${ }^{7,912}$ Physicians working in the PED were trained to consider US as a CT alternative for diagnostic tests that would reduce the radiation hazards associated with $\mathrm{CT}$. We also adopted a direct consulting system using a designated telephone to discuss concerns with radiologists on duty and to identify optimal and feasible alternative diagnostic methods. The decision to perform a CT scan was made by PED clinicians after physical examination and history taking. If an unnecessary CT exam occurred in the PED, feedback was provided to the PED physicians. Since 2009, PED physicians have applied the CT guidelines from the PECARN (Pediatric Emergency Care Applied Research Network) to identify minor head trauma in pediatric head trauma patients. ${ }^{19}$ In order to identify 
safety issues due to changes in the trends of CT and US usage, we collected data on ward and intensive care unit (ICU) admission rates during the study periods. This study defined severe ill pediatric patients as admitted to the ward or ICU of our hospital.

\section{Study settings}

To assess the yearly trends in CT scan utilization, we compared data before and after 2007, when the direct consulting system for reducing radiation was widely accepted. Pediatric patients were defined by age (under 19 years) and divided into three age groups: infants ( 0 to 2 years), children ( 3 to 12 years), and adolescents (12 to 18 years). We categorized the $\mathrm{CT}$ images into the brain and abdomen, two major groups comprising the majority of imaging studies in the PED. CT scans of the brain/head/neck and abdominal/genitourinary regions were defined as brain and abdominal regions, respectively. In contrast, only pediatric abdominal US examinations were included, because the abdomen is the region most commonly scanned by US in the PED. The annual CT and US use ratios of the age groups were calculated per 1,000 ED visits during the study period. The US/CT ratios for the abdominal region were also calculated. Radiologists performed all pediatric US examinations in our institution. Emergency physicians in the PED also performed US for some emergencies such as intussusception or major trauma. However, we did not include US performed by the ED physicians in this study because the exact numbers could not be extracted from the electronic medical records.

\section{Outcomes}

The primary outcome was the trend in CT usage overall, as well as for the anatomical regions, including the brain and abdomen as well as changes in total and abdominal US usage in pediatric populations during 15 years (2000 to 2014). The secondary outcome was change in the abdominal US/CT ratio in the PED before and after 2007.

\section{Statistical methods}

The categorical variables are expressed as numbers (\%). The annual trends in CT and US usage ratios and US/CT ratios for the abdominal region were calculated using Microsoft Excel 2007 (Microsoft, Redmond, WA, USA). A piecewise Poisson regression analysis was used to analyze the changing trends in CT and US use before and after 2007. The results of the regression analysis were adjusted by the annual number of visits. Piecewise linear regression analysis was used to analyze the changes in the trends and differences in US/CT ratios because these data were comprised of ratios. All statistical analyses were conducted using STATA ver. 13.0 (StataCorp, College Station, TX, USA).

\section{RESULTS}

\section{CT scan utilization}

During the 15-year study period, there were 196,371 visits and 12,996 (6.6\%) CT scans in the PED (Supplementary Table 1). Among all CT cases, 8,445 (65.0\%) brain CT scans were performed in the PED. In addition, 2,762 (21.3\%) abdominal CT scans were also performed in the PED. The CT scan rate per 1,000 PED visits decreased markedly after 2007, especially in infants and children. The CT scan rate per 1,000 PED visits rose steadily from 43.6 in 2000 and peaked at 116.7 in 2007. The rate started to drop in 2008 (106.8), reaching 36.8 in 2014. The only exception to this trend was the adolescent group, in which the rate per 1,000 patients increased and peaked in 2011 (215.0), then returned a level similar to that observed in 2007 (148.7) (Fig. 1 and Supplementary Table 2).

Comparison of the trends in CT use in overall pediatric patients before and after 2007 revealed significantly decreasing coefficient values of the differences $(-0.30 ; 95 \%$ confidence interval [Cl], -0.35 to -0.24 ) (Table 1). Comparison of the trends in CT use according to the anatomical region (brain or abdomen) based on age groups revealed statistically significant decreases in the coefficient values of the differences among groups, except for abdominal CT in adolescents (Table 1, Figs. 2 and 3). The trends in brain CT use in infants showed the most remarkable decreasing coefficient values of difference $\left(-0.42 ; 95 \% \mathrm{Cl}_{1}-0.51\right.$ to -0.33$)$.

\section{US utilization}

During the study period, 15,490 US studies were performed in the PED (7.9\% of all visitors), 12,424 (80.2\%) of which were abdominal US. The US rate per 1,000 PED visits increased until 2004 (101.2), then steadily decreased, reaching 54.9 in 2014. After dividing the US use rate per 1,000 PED visits into three pediatric age groups, the total US use in overall pediatric patients decreased slightly, except in some years. Analyses of the trends in US use rate per 1,000 PED visit according to the anatomical regions in each age group revealed increasing abdominal US rate per 1,000 PED visits through 2004 (83.6), with a generally decreasing rate afterward, reaching 43.2 in 2014 (Supplementary Tables 3 and 4).

Comparison of the trends in total US before and after 2007 showed slightly decreased coefficient values of differences. However, US use in children plateaued and increased slightly in adolescents. Abdominal US showed a similar trend to that of total US (Table 2). Fig. 4 compares the trends in abdominal US and CT scans during the study period. Unlike the above results, the overall pediatric patients showed statistically significant increases in 


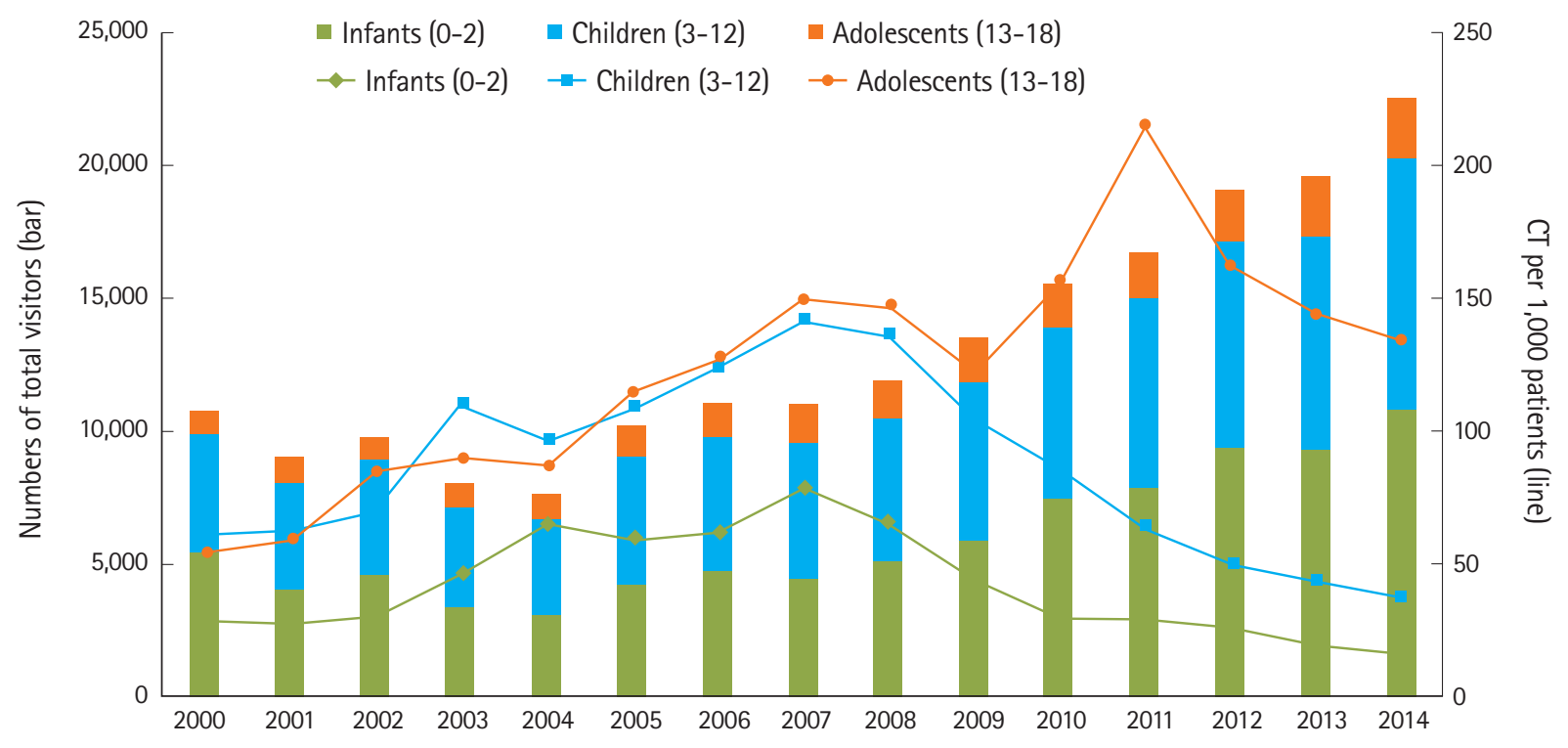

Fig. 1. Number of annual visits and trend in computed tomography (CT) use; 2000 to 2014. This figure shows the number of annual visits and CT use per 1,000 emergency department visits according to age group. The segmented bar chart indicates the number of visits according to age group during the study period, while the line graph shows the CT use rate per 1,000 emergency department visit according to age group.

Table 1. Piecewise Poisson regression analysis between two periods in CT use

\begin{tabular}{|c|c|c|c|c|c|c|c|c|c|c|}
\hline \multirow{2}{*}{$\begin{array}{l}\text { Anatomical } \\
\text { regions }\end{array}$} & \multirow{2}{*}{ Age group } & \multicolumn{3}{|c|}{ Before (2000-2006) } & \multicolumn{3}{|c|}{ After (2007-2014) } & \multicolumn{3}{|c|}{ Difference of trends between two periods } \\
\hline & & $\beta 1$ coef & $95 \% \mathrm{Cl}$ & P-value & $\beta 2$ coef & $95 \% \mathrm{Cl}$ & P-value & $\beta 2-\beta 1$ coef & $95 \% \mathrm{Cl}$ & P-value \\
\hline \multirow[t]{4}{*}{ Total $\mathrm{CT}^{\mathrm{a})}$} & Overall ${ }^{b)}$ & 0.15 & 0.13 to 0.18 & $<0.01$ & -0.14 & -0.20 to -0.09 & $<0.01$ & -0.30 & -0.35 to -0.24 & $<0.01$ \\
\hline & Infants & 0.15 & 0.11 to 0.20 & $<0.01$ & -0.19 & -0.29 to -0.10 & $<0.01$ & -0.35 & -0.43 to -0.27 & $<0.01$ \\
\hline & Children & 0.14 & 0.11 to 0.17 & $<0.01$ & -0.18 & -0.28 to -0.08 & $<0.01$ & -0.32 & -0.40 to -0.24 & $<0.01$ \\
\hline & Adolescents & 0.24 & 0.17 to 0.30 & $<0.01$ & 0.10 & 0.01 to 0.19 & 0.04 & -0.14 & -0.19 to -0.09 & $<0.01$ \\
\hline \multirow[t]{4}{*}{ Brain $\mathrm{CT}^{\mathrm{c}}$} & Overall & 0.12 & 0.10 to 0.14 & $<0.01$ & -0.20 & -0.25 to -0.14 & $<0.01$ & -0.32 & -0.37 to -0.27 & $<0.01$ \\
\hline & Infants & 0.14 & 0.10 to 0.19 & $<0.01$ & -0.27 & -0.37 to -0.18 & $<0.01$ & -0.42 & -0.51 to -0.33 & $<0.01$ \\
\hline & Children & 0.11 & 0.08 to 0.15 & $<0.01$ & -0.21 & -0.32 to -0.11 & $<0.01$ & -0.32 & -0.41 to -0.24 & $<0.01$ \\
\hline & Adolescents & 0.15 & 0.07 to 0.22 & $<0.01$ & -0.09 & -0.01 to 0.19 & 0.08 & -0.06 & -0.12 to 0.00 & 0.03 \\
\hline \multirow[t]{4}{*}{ Abdomen $\mathrm{CT}^{\mathrm{d})}$} & Overall & 0.28 & 0.24 to 0.32 & $<0.01$ & -0.03 & -0.13 to 0.06 & 0.48 & -0.31 & -0.41 to -0.22 & $<0.01$ \\
\hline & Infants & 0.18 & 0.15 to 0.20 & $<0.01$ & -0.03 & -0.21 to 0.15 & 0.73 & -0.21 & -0.39 to -0.03 & 0.03 \\
\hline & Children & 0.27 & 0.21 to 0.32 & $<0.01$ & -0.15 & -0.19 to -0.11 & $<0.01$ & -0.38 & -0.47 to -0.28 & $<0.01$ \\
\hline & Adolescents & 0.48 & 0.30 to 0.67 & $<0.01$ & 0.13 & 0.00 to 0.26 & 0.06 & -0.36 & -0.49 to -0.22 & $<0.01$ \\
\hline
\end{tabular}

$\mathrm{CT}$, computed tomography; coef, coefficient value; $\mathrm{Cl}$, confidence interval.

${ }^{a}$ Total CT use according to the pediatric age group. ${ }^{\text {b) Total }}$ CT use in all pediatric age groups. ${ }^{\mathrm{c} B}$ Brain, head, and neck regions. ${ }^{\mathrm{d}}$ Abdomen and genitourinary region.

the coefficient values of the differences after $2007(2.68 ; 95 \% \mathrm{Cl}$, 1.87 to 3.49 ), especially in infants. The difference was not statistically significant in adolescents, but the decreasing trend stopped after 2007 (4.73; 95\% Cl, 2.67 to 6.78) (Table 3).

\section{Admission rates}

During the study period, 35,488 patients in the PED were admitted to the ward (17.8\% of all visitors). In addition, 959 patients were admitted to the ICU ( $0.5 \%$ of all visitors). The ward and ICU admission rates were $17.2 \%$ and $0.6 \%$, respectively, in 2000 . In 2014, the admission rates were $17.8 \%$ and $0.5 \%$, respectively (Fig. 5).

\section{DISCUSSION}

In this study, we observed a decreasing trend in CT usage after 2007, when PED physicians and radiologists in our institution began to reduce unnecessary CT scans and other imaging modalities; the overall trend of abdominal US compared to CT in overall pediatric patients also significantly increased after 2007.

In recent years, there has been increasing awareness of radiation exposure and potential cancer risk from CT use. ${ }^{13}$ Consequently, physicians have tried to decrease CT scans in pediatric patients because of their increased radiation hazard. ${ }^{19,20}$ However, 


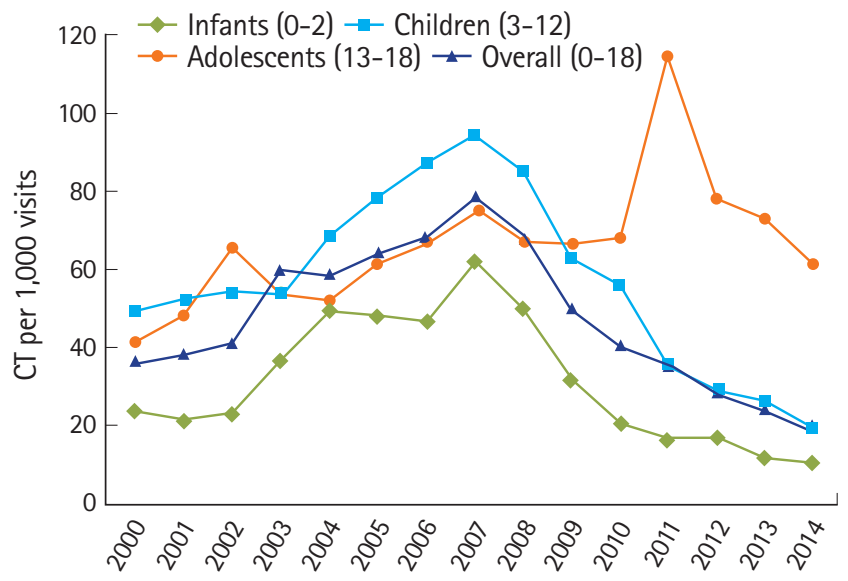

Fig. 2. Trend in brain, head, and neck computed tomography (CT) use according to age group from 2000 to 2014.

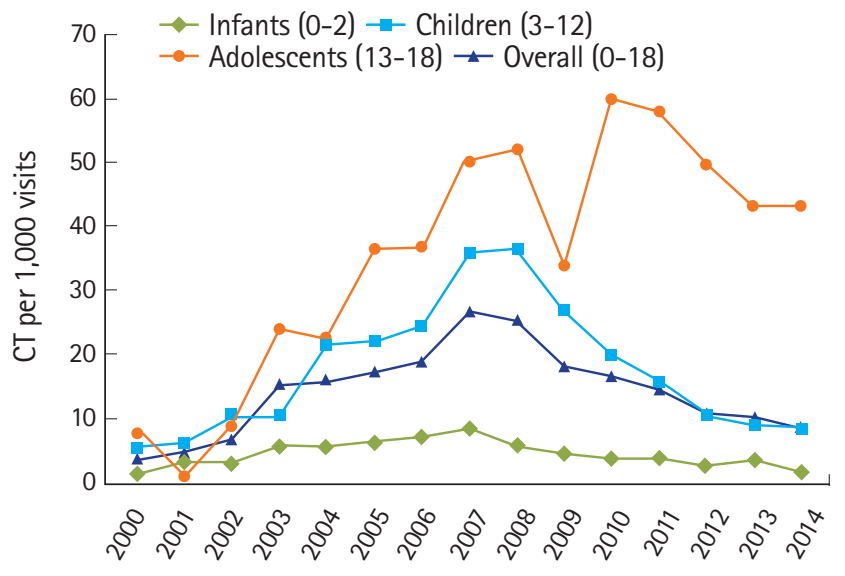

Fig. 3. Trend in abdominal and genitourinary region computed tomography (CT) use according to age group from 2000 to 2014.

Table 2. Piecewise Poisson regression analysis between two periods in US use

\begin{tabular}{|c|c|c|c|c|c|c|c|c|c|c|}
\hline \multirow{2}{*}{$\begin{array}{l}\text { Anatomical } \\
\text { regions }\end{array}$} & \multirow{2}{*}{ Age group } & \multicolumn{3}{|c|}{ Before (2000-2006) } & \multicolumn{3}{|c|}{ After (2007-2014) } & \multicolumn{3}{|c|}{ Difference of trends between two periods } \\
\hline & & $\beta 1$ coef & $95 \% \mathrm{Cl}$ & P-value & $\beta 2$ coef & $95 \% \mathrm{Cl}$ & P-value & $\beta 2-\beta 1$ coef & $95 \% \mathrm{Cl}$ & P-value \\
\hline \multirow[t]{4}{*}{ Total US } & Overall ${ }^{b)}$ & 0.02 & 0.01 to 0.03 & $<0.01$ & -0.05 & -0.09 to 0.00 & 0.03 & -0.07 & -0.11 to -0.03 & $<0.01$ \\
\hline & Infants & 0.02 & 0.00 to 0.04 & 0.13 & -0.14 & -0.21 to -0.08 & $<0.01$ & -0.16 & -0.24 to -0.08 & $<0.01$ \\
\hline & Children & 0.06 & 0.03 to 0.09 & $<0.01$ & 0.03 & -0.02 to 0.09 & 0.27 & -0.03 & -0.08 to 0.02 & 0.28 \\
\hline & Adolescents & 0.02 & -0.02 to 0.06 & 0.25 & 0.06 & 0.00 to 0.11 & 0.02 & 0.04 & 0.01 to 0.07 & 0.03 \\
\hline \multirow[t]{4}{*}{ Abdomen US ${ }^{c}$} & Overall & 0.03 & 0.02 to 0.04 & $<0.01$ & -0.04 & -0.09 to 0.01 & 0.13 & -0.07 & -0.12 to -0.02 & $<0.01$ \\
\hline & Infants & 0.03 & 0.00 to 0.06 & 0.02 & -0.15 & -0.23 to -0.08 & $<0.01$ & -0.19 & -0.28 to -0.09 & $<0.01$ \\
\hline & Children & 0.07 & 0.03 to 0.11 & $<0.01$ & 0.07 & 0.00 to 0.14 & 0.05 & 0.00 & -0.06 to 0.06 & 0.99 \\
\hline & Adolescents & 0.01 & -0.04 to 0.07 & 0.63 & 0.10 & 0.04 to 0.17 & $<0.01$ & 0.09 & 0.05 to 0.13 & $<0.01$ \\
\hline
\end{tabular}

US, ultrasound; coef, coefficient value; $\mathrm{Cl}$, confidence interval; PED, pediatric emergency department.

${ }^{a}$ Total US use according to the pediatric age group. ${ }^{\text {b } T o t a l ~ U S ~ u s e ~ i n ~ a l l ~ p e d i a t r i c ~ a g e ~ g r o u p s . ~}{ }^{\text {c) } A b d o m e n}$ and genitourinary region.

some studies on CT use in pediatric patients have reported increasing or unchanged rates of CT scan use., ${ }^{6,21}$

In contrast to these studies, a study on $\mathrm{CT}$ examination trends in PEDs in Korea showed increasing CT use in the pediatric population until the mid-2000s due to the advantages mentioned above; however, CT usage has decreased since 2007, similar to the findings of the current study. ${ }^{22}$ However, this previous study did not compare CT usage in relation to US usage in pediatric patients. Our study compared CT trends with US trends in pediatric patients as well as the ratio of CT and US usage in pediatric patients. One advantage of our study is that it provides more information regarding the trends in CT use as well as US trends in pediatric patients. These preliminary data are a starting point and may be useful for comparison to the results of future studies related to CT and US usage.

When CT scans were divided according to anatomical regions, the incidence of brain CT scans decreased in pediatric populations after 2007, with a particularly steep decline in pediatric CT use. This observation may be related to an increased awareness of ra- diation exposure hazards among parents and medical staff. In addition, the application of clinical decision rules proposed by previous studies to minimize unnecessary head CT scans, including a head CT study on trends in the PED, ${ }_{1}^{21}$ by ED medical staff specializing in pediatric emergency medicine also likely had a significant impact on the decreasing rate of CT scans. ${ }^{19,20}$

Nevertheless, the CT use, both overall and abdominal CT, steadily increased in the adolescent population. This finding is consistent with that of the 2012 Jahan study $^{6}$ on CT scan usage in pediatric patients presenting to the ED with abdominal pain. The authors suggested that the dependency on CT scans for diagnosis increases with age as the diversity and complexity of illness also increases. However, the coefficient values in the trends of CT use in adolescents after $2007(-0.14[95 \% \mathrm{Cl},-0.19$ to -0.09$]$ for total $\mathrm{CT}$, and -0.36 [95\% $\mathrm{Cl},-0.49$ to -0.22$]$ in abdominal $\mathrm{CT}$ ) decreased in the current study, perhaps due to increasing concern about radiation exposure and dedicated pediatric emergency physicians who tried to reduce unnecessary CT use in our hospital after 2007. 


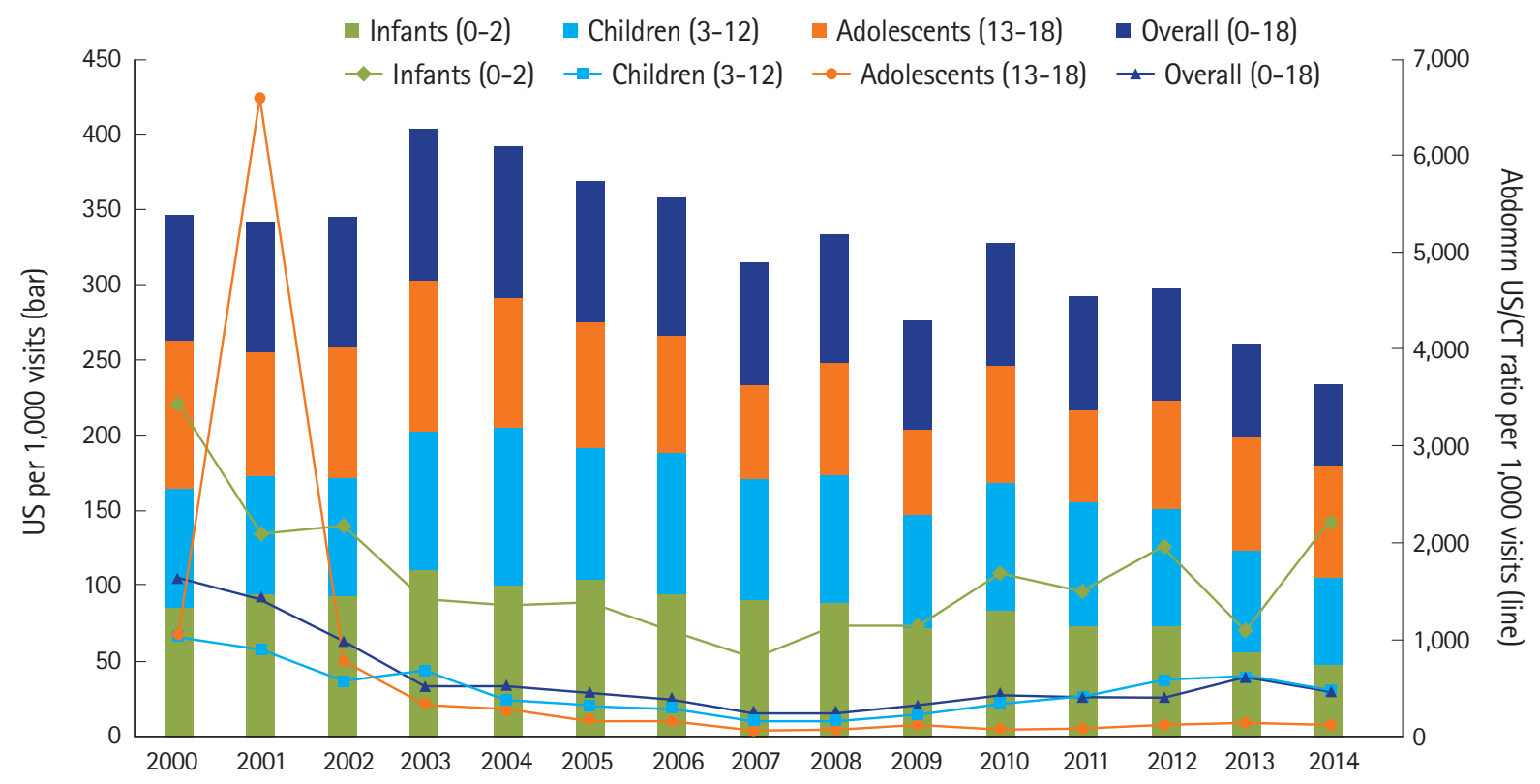

Fig. 4. Trend in ultrasound (US) use and ratio compared with computed tomography (CT) use for the abdominal and genitourinary regions according to age group. The segmented bar chart presents the rate of US use per 1,000 ED visits according to age group, while the graph chart shows the ratio of US use compared with CT use for imaging of the abdominal and genitourinary regions per 1,000 ED visits according to age group.

Table 3. Piecewise linear regression about ratio of ultrasound/CT in abdomen-genitourinary region

\begin{tabular}{|c|c|c|c|c|c|c|c|c|c|}
\hline \multirow{2}{*}{ Age group } & \multicolumn{3}{|c|}{ Before (2000-2006) } & \multicolumn{3}{|c|}{ After (2007-2014) } & \multicolumn{3}{|c|}{ Difference of trends between two periods } \\
\hline & $\beta 1$ coef & $95 \% \mathrm{Cl}$ & P-value & $\beta 2$ coef & $95 \% \mathrm{Cl}$ & P-value & $\beta 2-\beta 1$ coef & $95 \% \mathrm{Cl}$ & P-value \\
\hline Overalla) & -2.22 & -2.84 to -1.59 & $<0.01$ & 0.46 & -0.05 to 0.97 & 0.07 & 2.68 & 1.87 to 3.49 & $<0.01$ \\
\hline Infants & -3.33 & -4.92 to -1.74 & $<0.01$ & 1.40 & 0.10 to 2.70 & 0.04 & 4.73 & 2.67 to 6.78 & $<0.01$ \\
\hline Children & -1.29 & -1.65 to -0.93 & $<0.01$ & 0.69 & 0.40 to 0.99 & $<0.01$ & 1.98 & 1.52 to 2.45 & $<0.01$ \\
\hline Adolescents & -5.75 & -11.85 to 0.35 & 0.06 & 0.07 & -4.91 to 5.05 & 0.03 & 5.82 & -2.06 to 13.69 & 0.13 \\
\hline
\end{tabular}

$\mathrm{CT}$, computed tomography; coef, coefficient value; $\mathrm{Cl}$, confidence interval; $\mathrm{PED}$, pediatric emergency department.

${ }^{a)}$ Ultrasound/CT ratio in all pediatric age groups.

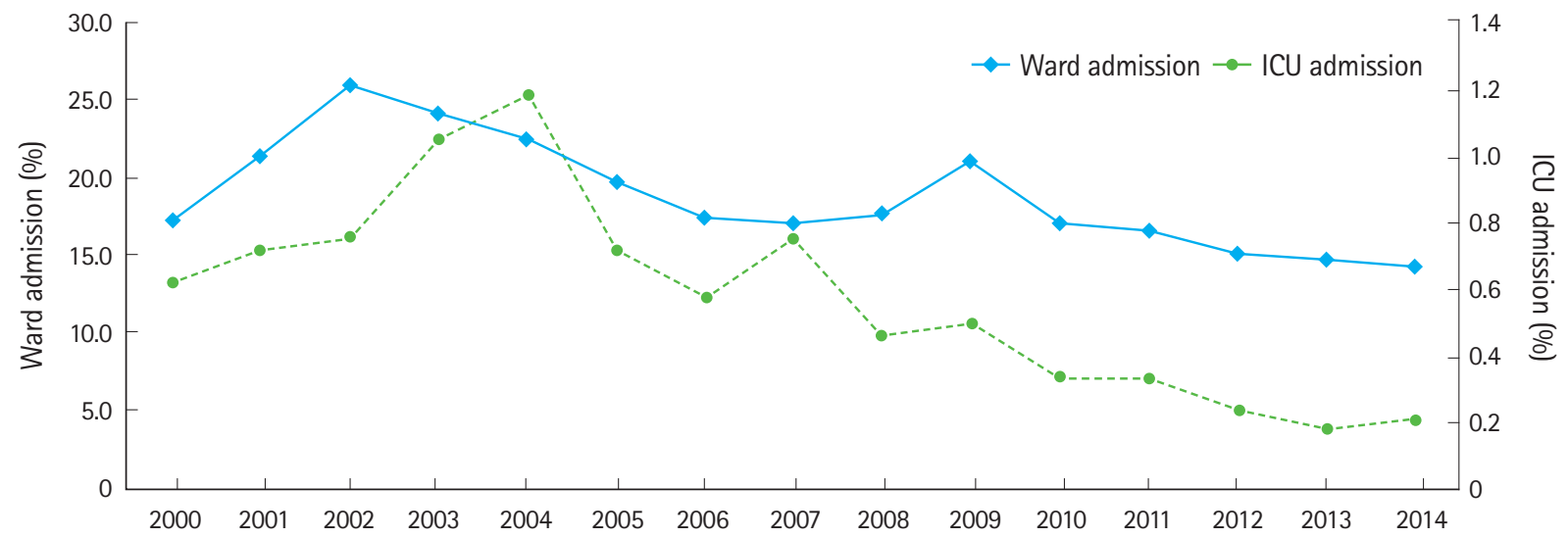

Fig. 5. Proportions of admissions to the wards and intensive care units (ICUs) during the study period.

Although CT is more accurate than US, US has many advantages for diagnosis in the PED. ${ }^{23,24}$ One advantage is the lack of radiation exposure. US cannot entirely replace $\mathrm{CT}$ for diagnosis in the ED but can reduce unnecessary CT use. ${ }^{25}$ We, therefore, evaluated the trends in US use in the PED. In this study, US usage in the PED did not show a steadily increasing trend, instead tending 
to decrease. However, the US/CT ratio in the overall pediatric patients increased significantly after 2007. The increase was not significant in the adolescent group during this time period, but the decreasing ratio was not observed after 2007. This result may be due to decreased CT use rather than increased US use in the PED. In our PED, emergency physicians exclusively examine pediatric patients and determine the appropriate diagnostic modalities. Radiologists for these pediatric patients then perform US examinations or CT scans. They also try to reduce unnecessary CT scans. The proportions of severely ill pediatric patients admitted to the ward and ICU through our ED did not change significantly from 2000 to 2014. The observation of the increasing trend in patients visiting our PED without significantly different proportions of severely ill patients may have been due to the efforts of pediatric ED physicians and radiologists in our institution to reduce CT use in pediatric patients. Based on these findings, it is likely that the US/ CT ratio will continue to increase, leading to further decreases in the risk of radiation exposure among children in the ED.

Our study had some limitations. First, it was based on data collected from a single tertiary referral hospital located in the capital city; thus, it does not represent other medical facilities with different capacities and environments. Second, the retrospective nature of this study prevented us from determining the exact indications for the ED physicians in the PED to perform US and CT scans. Further prospective studies are necessary. Third, because we did not know the effect of the decreased CT scan rates and increased ratio of US/CT use on prognosis of pediatric patients we cannot definitely conclude whether this trend is a positive one in pediatric patients. Lastly, data on bedside US in pediatric patients was not included due to accessibility. If these data were included in our study, the US/CT ratio would likely increase; however, additional prospective studies are necessary to assess this hypothesis.

In summary, we observed a decreasing trend in CT use in overall pediatric patients after 2007. While pediatric US use did not show a corresponding increasing trend, the US/CT ratios did increase in overall pediatric patients except for adolescents. This result was likely due to the efforts of ED physicians and radiologists in our PED to reduce unnecessary CT use. To our knowledge, the use of US/CT ratios in this study is a new tool to assess the trends in US and CT use in similar groups. We hope that the findings of this study will provide a preliminary picture of the current state of CT use.

\section{CONFLICT OF INTEREST}

No potential conflict of interest relevant to this article was reported.

\section{SUPPLEMENTARY MATERIALS}

Supplementary materials are available from: https://doi.org/10.15441/ ceem.16.192.

Supplementary Table 1. Annual visits at the PED and CT use from 2000 to 2014.

Supplementary Table 2. The rate of CT use per 1,000 visits at the PED from 2000 to 2014.

Supplementary Table 3. US use from 2000 to 2014.

Supplementary Table 4. The rate of US use per 1,000 visits at the PED from 2000 to 2014.

\section{REFERENCES}

1. Hess EP, Haas LR, Shah ND, Stroebel RJ, Denham CR, Swensen SJ. Trends in computed tomography utilization rates: a longitudinal practice-based study. J Patient Saf 2014;10:52-8.

2. Broder J, Fordham LA, Warshauer DM. Increasing utilization of computed tomography in the pediatric emergency department, 2000-2006. Emerg Radiol 2007;14:227-32.

3. Ahn S, Kim WY, Lim KS, et al. Advanced radiology utilization in a tertiary care emergency department from 2001 to 2010. PLoS One 2014;9:e112650.

4. Kocher KE, Meurer WJ, Fazel R, Scott PA, Krumholz HM, Nallamothu BK. National trends in use of computed tomography in the emergency department. Ann Emerg Med 2011;58:45262.

5. Oh HY, Kim EY, Cho J, et al. Trends of CT use in the adult emergency department in a tertiary academic hospital of Korea during 2001-2010. Korean J Radiol 2012;13:536-40.

6. Fahimi J, Herring A, Harries A, Gonzales R, Alter H. Computed tomography use among children presenting to emergency departments with abdominal pain. Pediatrics 2012;130: e1069-75.

7. Brenner D, Elliston $C$, Hall E, Berdon W. Estimated risks of radiation-induced fatal cancer from pediatric CT. AJR Am J Roentgenol 2001;176:289-96.

8. Kirpalani $H$, Nahmias $C$. Radiation risk to children from computed tomography. Pediatrics 2008;121:449-50.

9. Brody AS, Frush DP, Huda W, Brent RL; American Academy of Pediatrics Section on Radiology. Radiation risk to children from computed tomography. Pediatrics 2007;120:677-82.

10. Mathews JD, Forsythe AV, Brady Z, et al. Cancer risk in 680,000 people exposed to computed tomography scans in childhood or adolescence: data linkage study of 11 million Australians. BMJ 2013;346:f2360.

11. Wakeford R. The risk of childhood leukaemia following exposure 
to ionizing radiation: a review. J Radiol Prot 2013;33:1-25.

12. Boutis K, Fischer J, Freedman SB, Thomas KE. Radiation exposure from imaging tests in pediatric emergency medicine: a survey of physician knowledge and risk disclosure practices. J Emerg Med 2014;47:36-44.

13. Brenner DJ, Hall EJ. Computed tomography: an increasing source of radiation exposure. N Engl J Med 2007;357:227784.

14. Coco AS, O'Gurek DT. Increased emergency department computed tomography use for common chest symptoms without clear patient benefits. J Am Board Fam Med 2012;25:33-41.

15. Journy N, Ancelet $S$, Rehel JL, et al. Predicted cancer risks induced by computed tomography examinations during childhood, by a quantitative risk assessment approach. Radiat Environ Biophys 2014;53:39-54.

16. Miglioretti DL, Johnson $E$, Williams $A$, et al. The use of computed tomography in pediatrics and the associated radiation exposure and estimated cancer risk. JAMA Pediatr 2013;167: 700-7.

17. Morton RP, Reynolds RM, Ramakrishna R, et al. Low-dose head computed tomography in children: a single institutional experience in pediatric radiation risk reduction: clinical article. J Neurosurg Pediatr 2013;12:406-10.

18. Almohiy $\mathrm{H}$. Paediatric computed tomography radiation dose: a review of the global dilemma. World J Radiol 2014;6:1-6.
19. Kuppermann N, Holmes JF, Dayan PS, et al. Identification of children at very low risk of clinically-important brain injuries after head trauma: a prospective cohort study. Lancet 2009; 374:1160-70.

20. Holmes JF, Lillis $K$, Monroe $D$, et al. Identifying children at very low risk of clinically important blunt abdominal injuries. Ann Emerg Med 2013;62:107-16.

21. Menoch MJ, Hirsh DA, Khan NS, Simon HK, Sturm JJ. Trends in computed tomography utilization in the pediatric emergency department. Pediatrics 2012;129:e690-7.

22. Oh HY, Kim EY, Kim JE, et al. Trends of CT use in the pediatric emergency department in a tertiary academic hospital of Korea during 2001-2010. Korean J Radiol 2012;13:771-5.

23. Leeson K, Leeson B. Pediatric ultrasound: applications in the emergency department. Emerg Med Clin North Am 2013;31: 809-29.

24. Le J, Kurian J, Cohen HW, Weinberg G, Scheinfeld MH. Do clinical outcomes suffer during transition to an ultrasound-first paradigm for the evaluation of acute appendicitis in children? AJR Am J Roentgenol 2013;201:1348-52.

25. Blitman NM, Anwar M, Brady KB, Taragin BH, Freeman K. Value of focused appendicitis ultrasound and alvarado score in predicting appendicitis in children: can we reduce the use of CT? AJR Am J Roentgenol 2015;204:W707-12. 
Supplementary Table 1. Annual visits at the PED and CT use from 2000 to 2014

\begin{tabular}{|c|c|c|c|c|c|c|c|c|c|c|c|c|c|c|c|c|}
\hline & Age group & 2000 & 2001 & 2002 & 2003 & 2004 & 2005 & 2006 & 2007 & 2008 & 2009 & 2010 & 2011 & 2012 & 2013 & 2014 \\
\hline \multirow[t]{3}{*}{ Annual visits at the PED } & Overall(b) & 10,785 & 9,018 & 9,778 & 8,057 & 7,671 & 10,236 & 11,069 & 11,020 & 11,928 & 13,555 & 15,578 & 16,778 & 19,005 & 19,301 & 22,592 \\
\hline & Infants & 5,433 & 4,034 & 4,572 & 3,343 & 3,041 & 4,245 & 4,690 & 4,456 & 5,145 & 5,913 & 7,503 & 7,885 & 9,412 & 9,265 & 10,858 \\
\hline & Adolescents & 871 & 935 & 869 & 908 & 962 & 1,167 & 1,294 & 1,453 & 1,451 & 1,700 & 1,675 & 1,786 & 1,860 & 1,978 & 2,303 \\
\hline \multirow[t]{3}{*}{ Total CT at the PED } & Overall & 470 & 415 & 511 & 656 & 633 & 909 & 1,079 & 1,286 & 1,274 & 1,088 & 1,031 & 1,058 & 930 & 825 & 831 \\
\hline & Infants & 153 & 108 & 137 & 155 & 197 & 252 & 288 & 348 & 335 & 259 & 221 & 222 & 242 & 190 & 167 \\
\hline & Adolescents & 47 & 55 & 73 & 82 & 83 & 133 & 164 & 216 & 213 & 208 & 261 & 384 & 302 & 286 & 309 \\
\hline \multirow[t]{4}{*}{ Brain CT at the PED ${ }^{d)}$} & Overall & 387 & 342 & 397 & 480 & 450 & 650 & 751 & 866 & 806 & 675 & 627 & 587 & 529 & 459 & 439 \\
\hline & Infants & 131 & 87 & 106 & 122 & 150 & 202 & 219 & 277 & 256 & 188 & 157 & 129 & 161 & 106 & 117 \\
\hline & Children & 220 & 210 & 234 & 309 & 250 & 376 & 445 & 480 & 453 & 374 & 357 & 253 & 223 & 209 & 181 \\
\hline & Adolescents & 36 & 45 & 57 & 49 & 50 & 72 & 87 & 109 & 97 & 113 & 113 & 205 & 145 & 144 & 141 \\
\hline
\end{tabular}

Values are presented as numbers.

$\mathrm{CT}$, computed tomography; PED, pediatric emergency department.

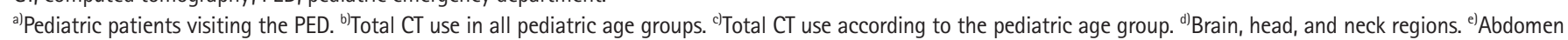
and genitourinary region.

Supplementary Table 2. The rate of CT use per 1,000 visits at the PED from 2000 to 2014

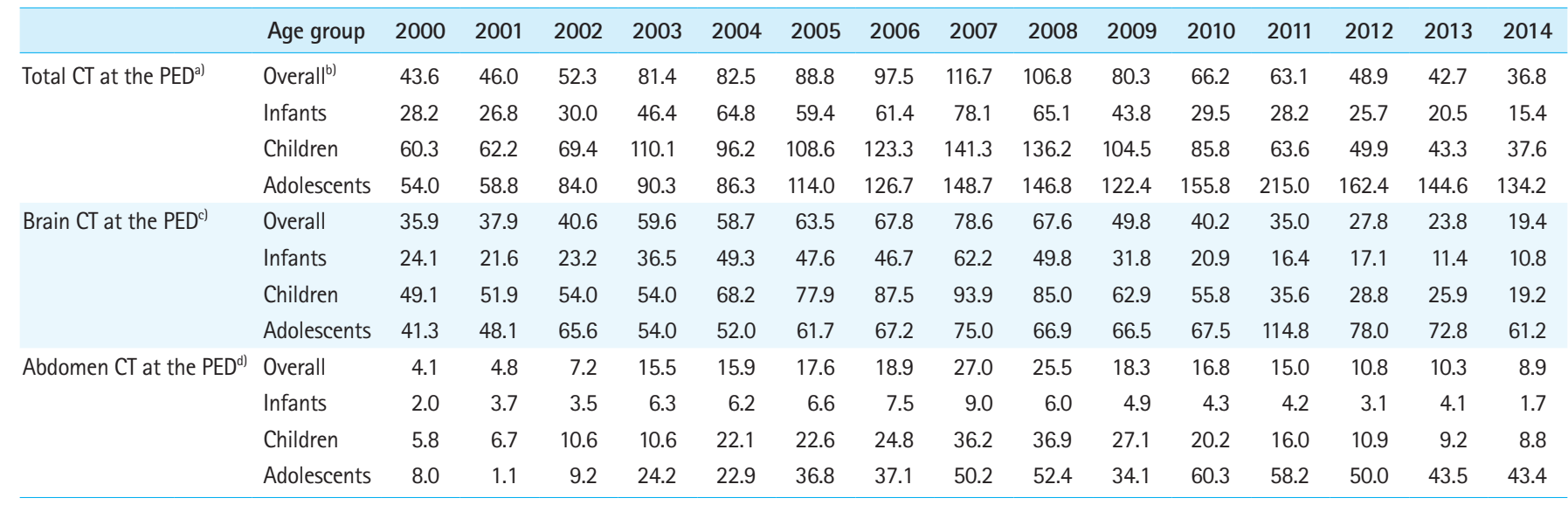

CT, computed tomography; PED; pediatric emergency department.

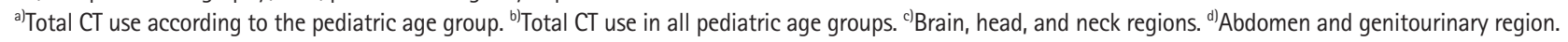


Supplementary Table 3. US use from 2000 to 2014

\begin{tabular}{|c|c|c|c|c|c|c|c|c|c|c|c|c|c|c|c|c|}
\hline & Age group & 2000 & 2001 & 2002 & 2003 & 2004 & 2005 & 2006 & 2007 & 2008 & 2009 & 2010 & 2011 & 2012 & 2013 & 2014 \\
\hline \multirow[t]{4}{*}{ Total US at the PED } & Overall ${ }^{b)}$ & 906 & 778 & 847 & 814 & 776 & 965 & 1024 & 907 & 1,021 & 976 & 1,302 & 1,279 & 1,439 & 1,216 & 1,240 \\
\hline & Infants & 470 & 388 & 429 & 369 & 306 & 447 & 442 & 409 & 466 & 432 & 633 & 586 & 702 & 529 & 519 \\
\hline & Children & 349 & 312 & 343 & 354 & 387 & 421 & 481 & 407 & 446 & 448 & 539 & 583 & 606 & 538 & 552 \\
\hline & Adolescents & 87 & 78 & 75 & 91 & 83 & 97 & 101 & 91 & 109 & 96 & 130 & 110 & 131 & 149 & 169 \\
\hline \multirow[t]{4}{*}{ Abdomen US at the PED } & Overall & 728 & 628 & 675 & 647 & 641 & 817 & 840 & 679 & 746 & 764 & 1,080 & 1,049 & 1,171 & 982 & 977 \\
\hline & Infants & 378 & 317 & 349 & 298 & 265 & 385 & 379 & 326 & 360 & 343 & 545 & 496 & 571 & 415 & 424 \\
\hline & Children & 274 & 245 & 263 & 276 & 318 & 350 & 380 & 293 & 320 & 351 & 442 & 467 & 488 & 444 & 427 \\
\hline & Adolescents & 76 & 66 & 63 & 73 & 58 & 82 & 81 & 60 & 66 & 70 & 93 & 86 & 112 & 123 & 126 \\
\hline
\end{tabular}

Values are presented as numbers.

US, ultrasound; PED, pediatric emergency department.

${ }^{\text {a) }}$ Total US use according to the pediatric age group. ${ }^{\text {b) }}$ Total US use in all pediatric age groups. ${ }^{\mathrm{c}}$ Abdomen and genitourinary region.

Supplementary Table 4. The rate of US use per 1,000 visits at the PED from 2000 to 2014

\begin{tabular}{|c|c|c|c|c|c|c|c|c|c|c|c|c|c|c|c|c|}
\hline & Age group & 2000 & 2001 & 2002 & 2003 & 2004 & 2005 & 2006 & 2007 & 2008 & 2009 & 2010 & 2011 & 2012 & 2013 & 2014 \\
\hline \multirow[t]{4}{*}{ Total US at the PED } & Overall(b) & 84.0 & 86.3 & 86.6 & 101.0 & 101.2 & 94.3 & 92.5 & 82.3 & 85.6 & 72.0 & 83.6 & 76.2 & 75.7 & 63.0 & 54.9 \\
\hline & Infants & 86.5 & 96.2 & 93.8 & 110.4 & 100.6 & 105.3 & 94.2 & 91.8 & 90.6 & 73.1 & 84.4 & 74.3 & 74.6 & 57.1 & 47.8 \\
\hline & Children & 77.9 & 77.1 & 79.1 & 93.0 & 105.5 & 87.3 & 94.6 & 79.6 & 83.6 & 75.4 & 84.2 & 82.0 & 78.4 & 66.8 & 58.5 \\
\hline & Adolescents & 99.9 & 83.4 & 86.3 & 100.2 & 86.3 & 83.1 & 78.1 & 62.6 & 75.1 & 56.5 & 77.6 & 61.6 & 70.4 & 75.3 & 73.4 \\
\hline \multirow[t]{4}{*}{ Abdomen US at the PED } & Overall & 67.5 & 69.6 & 69.0 & 80.3 & 83.6 & 79.8 & 75.9 & 61.6 & 62.5 & 56.4 & 69.3 & 62.5 & 44.3 & 61.6 & 43.2 \\
\hline & Infants & 69.6 & 78.6 & 76.3 & 89.1 & 87.1 & 90.7 & 80.8 & 73.2 & 70.0 & 58.0 & 72.6 & 62.9 & 60.7 & 44.8 & 39.0 \\
\hline & Children & 61.1 & 60.5 & 60.6 & 72.5 & 86.7 & 72.6 & 74.7 & 57.3 & 60.0 & 59.1 & 69.1 & 65.7 & 63.1 & 55.1 & 45.3 \\
\hline & Adolescents & 87.3 & 70.6 & 72.5 & 80.4 & 60.3 & 70.3 & 62.6 & 41.3 & 45.5 & 41.2 & 55.5 & 48.2 & 60.2 & 62.2 & 54.7 \\
\hline
\end{tabular}

US, ultrasound; PED, pediatric emergency deparment.

${ }^{a}$ )Total US use according to the pediatric age group. ${ }^{b}$ Total US use in all pediatric age groups. ${ }^{c}$ Abdomen and genitourinary region. 